\title{
IMPACT OF THE USE OF BLACKBOARD ON PERFORMANCE OF ACCOUNTING STUDENTS
}

\author{
Laurence Lawson-Body, University of North Dakota, laurence.lawsonbody@business.und.edu \\ Lori Willoughby, Minot State University, lori.willoughby@minotstateu.edu \\ Assion Lawson-Body, University of North Dakota, alawsonbody@business.und.edu
}

\begin{abstract}
Teachers use Blackboard to monitor students' progress and to boost students' performance. However, not much is known about the effect of the use of Blackboard on performance of accounting students. The objective of this study is to conduct empirical analysis to examine the impact of using Blackboard in accounting courses on students' performance. This objective raised important research questions. To answer these questions, interview data were collected from accounting students. We used content analysis to analyze the interview data. Some of the expected factors were found in all 4 categories: static Blackboard category, dynamic Blackboard category, integrative Blackboard category and accounting students' performance category. The findings should help accounting students to understand that static Backboard is not the solution to pass accounting courses. Rather, we found that the use of dynamic and integrative Blackboard is more suitable to accounting students because of the difficult nature of accounting.
\end{abstract}

Keywords: Blackboard, Accounting, Student Performance, Education, Information Technology

\section{INTRODUCTION}

Using Blackboard to adapt learning instructions to the needs of students is increasingly becoming a teaching method in education. Blackboard is defined as a web-based learning management system (LMS) designed to support fully online courses or provide a space for face-to-face course interactions [10]. Blackboard is a learning system that provides a virtual learning environment and course management system [1]. Blackboard is also a tool that allows faculty to add resources for students to access online and has some features for students to enhance teaching and learning efforts [10]. Previous research mentioned that opinion and attitudes of the user can affect any technology implementation [1]. Cost and technical problems are also a major concern for Blackboard application and implementation [1]. In some universities, it is observed that Blackboard has been used for technology's sake rather than achieving sound educational benefits [1]. Therefore, the effective utilization of the Blackboard learning system mainly depends on students and faculty members' background, readiness and acceptance of such system [1]. Furthermore, Blackboard is a technology that evolves and frequent training is an important factor to facilitate its maximum utilization [1].

Many teachers use Blackboard to monitor students' progress carefully and to boost students' performance. A student's performance in an educational institution is the measure of academic success, or how well a student meets standards set out by local government and the institution itself [11]. The tracking of academic performance fulfills a number of purposes. Areas of achievement and failure in a student's academic career need to be evaluated in order to foster improvement and make full use of the learning process.

However, not much is known about the effect of the use of Blackboard on performance of accounting students. We noticed that in information technology education, and accounting literature few authors have studied the impact of the use of Blackboard in teaching accounting classes. This research is conducted to fill this gap in literature. Therefore, the objective of this study is to conduct empirical analysis to examine the impact of using Blackboard in accounting courses on students' performance. The research questions are the following: how can the use of Blackboard contribute to the passing or failing in accounting classes? Do accounting students rely more than other students on the information their instructors post on Blackboard? How do the quality and quantity of the content on Blackboard impact accounting students' performance? 
This paper is organized as follows: the first section presents the theoretical background, the second sections bears on literature review and the conceptual framework. The third section addresses the methodology. The fourth section outlines the findings. The fifth section provides the discussion, and the last part presents the conclusion and implications.

\section{Theoretical Background}

The use of Blackboard technology to support teaching and learning is part of creative education efforts. It is why the theory of creativity is used as the theoretical underpinning in this study. In this study we consider the use of Blackboard as a creative education that can be adapted to impact student academic performance. The use of Blackboard can foster students to be more creative in accounting courses. In fact, theory of creativity is based on the creative psychology and thinking of people [4]. It is a human-oriented theory on the development of creativity [4]. Creativity development science is mainly created to provide and support creative education. Theory of creativity is then connected to creative information technology education.

\section{LITERATURE REVIEW}

Although commercial enterprises were the first to leverage off the digital economy, business schools, colleges and universities were not isolated from these changes [14]. When technology is used in innovative ways it can lead to improvement in learning and teaching [5]. The colleges and the universities have implanted Blackboard systems as one of the ways to answer the needs of students in "the technology world" [10]. The use of Blackboard favors students' freedom to decide when each online lesson will be learned. It also provides lack of dependence on the time constraints of the lecturer. In terms of availability, students can access Blackboard via the internet at anytime and anywhere. Even though students may appreciate its convenience, the use of Blackboard can have some negative aspects. It may lack interpersonal and direct interaction between students and teachers.

According to Bouhnik and Marcus cited in [10], when compared to the face-to-face learning format, the use of Blackboard requires students to dedicate more time to learn the subject matter. The use of Blackboard lacks a learning atmosphere because there are fewer opportunities for contact or discussions with other students and teachers [10]. For instance, when students have questions or concerns, lack of immediate clarification can slow down the learning process. Also some research has indicated that passive online learning produces poorer learning outcomes [6].

\section{CONCEPTUAL FRAMEWORK}

The purpose of this study is to use qualitative data to examine the relationship between the use of Blackboard and accounting students' performance. Figure 1 shows that there are different types of Blackboard which can be used: Static Blackboard, Dynamic Blackboard, and Integrative Blackboard. Figure 1 also shows that the level of accounting students' performance can be divided into five categories: the basic level of understanding of the students, the students' perception of the exams' levels of difficulty, the motivation of the students in class, the frequency of the students seeking feedback in class, and the level of class participation of the students.

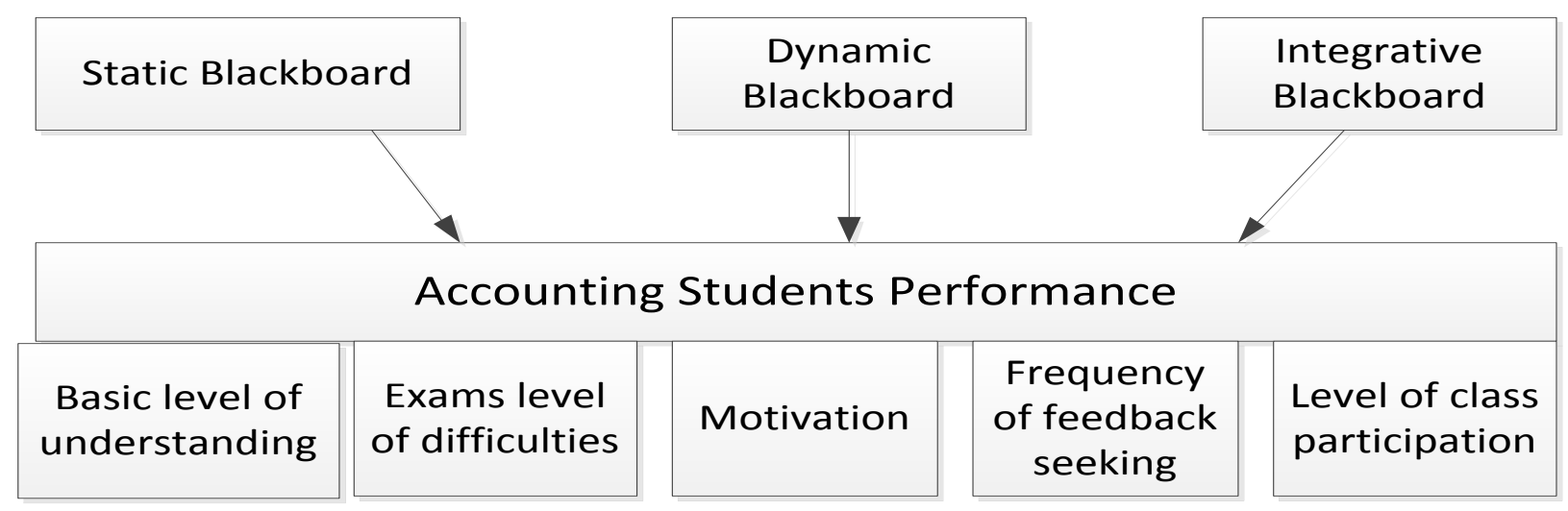

Figure 1. Blackboard-Student-Performance Framework 


\section{Static Blackboard}

Static blackboard is the informational Blackboard which can be used to inform students about course publications and announcements [8]. Blackboard provides many tools for the students and teachers [12]. The tools are announcements which allow students to know the latest news, notifications, information and calendar; tasks which enable students to know what they have to do, it also allows them to organize according to the subject or personal visions; and grade center which provide grades obtained in examinations or tests [1]. Blackboard has also many features accessible to instructors and students including course documents, syllabus, and hyperlinks [1]. While using the informational Blackboard, students can visit it, read or print information posted on it [16].

\section{Dynamic Blackboard}

Dynamic Blackboard is the interactive Blackboard: in addition to all functions of the informational Blackboard, it can be used for interactions and exchanges with the instructor [16]. It can also be used for interactions among students through the use of WIMBA, WIKI and discussion forum. On the interactions side, the Blackboard facilitates communication between students and the instructor through announcements, a discussion board and email or instant messaging [3]. Moreover, it improves communication through discussions and virtual classroom [1]. This type of Blackboard allows students to download course materials like videos and interactive PowerPoint slides [8]. Dynamic Blackboard can also contain forms students can use to order textbooks and make payments [16]. This type of Blackboard can contain registration forms allowing students to join discussion groups and participate in education forums [12].

\section{Integrative Blackboard}

Integrative Blackboard can contain all functions found in the interactive Blackboard [8]. In addition, it can be integrated to software like "Respondus" which allows students to take exams on Blackboard. The exams are then automatically graded by Blackboard [3]. The students' grades are automatically reported in the grade center of Blackboard [3]. The integrative Blackboard can also be compatible or connected to software like "Adobe Connect Professional", allowing students to attend a synchronized lecture online. Sometimes, the integration between Blackboard and "Adobe Connect professional" can allow students to attend hybrid classroom sessions when some students are online and some are on-campus. For this type of Blackboard, security can be an issue. Security can be defined in this context like the degree of confidentiality and authentication the college perceives students may have on its Blackboard [16]. The students should feel safe in their educational activities they are conducting on the Blackboard. Some authors suggest to have some of the security standards and protocols for the Internet used to protect data and privacy visible on Blackboard to the students [12]. On the opposite side, college administrators and teachers should require some control safeguards against plagiarism on Blackboard, specially, when students should take exams using proctors. Actually, taking the test online may require a proctor. A proctor designation procedure should be available on Blackboard. But how safe that procedure can be is another challenge faced by this type of Blackboard. Another challenge presented by this type of Blackboard is the seriousness of the students. Most of the time the instructors could not see students through the presentation videoconference. Some students keep the video on but are not attending the course session. The last challenge is the technical issues during the synchronized class meetings [8]. Many universities have put in place technical support teams to overcome or minimize these technical challenges [12].

\section{Accounting Students' Performance}

Many studies have measured student academic performance using the final grades scored in the particular courses [11]. Some studies used GPAs (grade point averages) to identify students who perform well or not [11]. In this qualitative study, we will not use these quantitative or numeric data to measure accounting students' performance. Instead, we will use qualitative measures to show how the use of Blackboard can contribute to passing or failing in accounting classes. More specifically, we adopt the basic level of understanding of the students, the students' perception of the exams' levels of difficulty, the motivation of the students in classes, the frequency of the students seeking feedback in classes, and the level of class participation of the students. 


\section{METHODOLOGY}

\section{Site Selection and Participants}

A qualitative study is performed to meet the goal of this study. Therefore, the participants are randomly selected students from a college of business of a university in USA who are majoring in accounting. The accounting curriculum contains 96 credits. But 150 credits are required before students can take the CPA exam. More than half of the participants are in lower level or introductory courses and the remaining participants are in the upper level or advanced accounting courses. Faculty members of the college of business were asked to announce the research project to students in their classes. Students who are interested in participating must be majoring in accounting. Interested students contacted the researcher and set up appointment for the interviews. The number of students interviewed is five.

\section{Data Collection}

For the data collection procedure, we had face-to-face in-depth interviews with accounting students. The interviews were audio recorded, and unstructured. The interviews were conducted with the randomly selected students who are majoring in accounting. Before the interviews, we developed an interview guide or schedule that contains openended questions. Next, the questions of the interview were sent to Instructional Review Board (IRB) for permission to conduct the interviews. The participating students were taking accounting classes during the semester of spring 2015 when the interviews took place. Each interview lasted for 45 minutes per student. We asked the students to sign a consent form before the interview took place. We also addressed the terms of confidentiality with the interviewees, explained to them how to get in touch with us, and let them know that we intended to share the findings with them.

\section{Content Analysis and Validity}

Qualitative Content Analysis (QCA) is a method of interpreting narrative material and, thus, has been associated with coding and classifying processes used in some types of qualitative research $[9,15,2]$. QCA is defined as systematic text analysis used to examine meaningful and symbolic content of qualitative data [13, 2]. Thematic content analysis is useful in our study because it is a method of analysis that can easily accommodate large amounts of data [9].

Concerning reliability of the study, two judges listened to the tapes and generated the transcripts of the interviews. Next, both judges read the interviews' transcripts or data and found initial major themes. Then, each student response was coded depending on the themes that spontaneously emerged from the data. Both judges conducted the above process separately and compared their individual results to find the percentage of agreement and disagreement between judges. Both judges reached about $90 \%$ of agreement and only $10 \%$ of disagreement. This is because many similar studies which have $90 \%$ of agreements were found satisfactory. Major themes identified by the two judges were interpreted further. We compared the categories found by both judges to the relationships we described in our conceptual framework.

\section{The Findings}

After the content analysis and the reliability tests were conducted, all factors which were found fell in the static Blackboard, dynamic Blackboard, integrative Blackboard and accounting students' performance categories. As shown in Table 1, some of the expected factors were found in all 4 categories. 
Table 1. Factors per Category

\begin{tabular}{|l|l|}
\hline \multicolumn{1}{|c|}{ Categories } & \\
\hline Static Blackboard Category & Lack of self-discipline \\
\cline { 2 - 3 } & Lack of a learning atmosphere \\
\cline { 2 - 2 } & High level of relying on solutions key \\
\cline { 2 - 2 } & Lack of class attendance \\
\cline { 2 - 2 } & Increased learning by reading \\
\hline \multirow{5}{*}{ Dynamic Blackboard category } & Availability of information in real time \\
\cline { 2 - 2 } & Quick and instant grading \\
\cline { 2 - 2 } & Improved communication \\
\cline { 2 - 2 } & Improved two-way interactions \\
\hline & Synchronized online sessions \\
\cline { 2 - 2 } & Online classroom discussions and problem solving \\
\cline { 2 - 2 } & Automated traditional face-to-face learning \\
\cline { 2 - 2 } & Effective application of the accounting rules, principles and assumptions. \\
\cline { 2 - 2 } & Security and privacy concerns \\
\hline Accounting Students Performance & Students class participation \\
\cline { 2 - 2 } & Quick feedback \\
\cline { 2 - 2 } & Boost of the basic level of understanding \\
\cline { 2 - 2 } & Motivation \\
\hline
\end{tabular}

\section{DISCUSSION}

Our findings indicated that the use of static Blackboard should be minimized in order to achieve a high level of selfdiscipline for accounting students. This is because accounting students wait for the instructors to post the answer key on Blackboard instead of doing the exercises themselves. This is reflected by the following declaration collected during the interview:

The home page of static Blackboard presents many links directing me to the answer keys of exercises. I found that helpful because I used the answer key to better understand the statement of the exercises or in-class activities. Posting the answer keys of exercises on Blackboard allows me to save time and get concentrated on the assignments of other courses which do not have assignments based on numbers like accounting topics. I found the use of Blackboard useful in that way. Blackboard is flexible and that it can help the student to have a durable relationship with its instructors. Static Blackboard informs me about publications concerning my accounting activities.

We found that learning accounting topics requires more learning by doing than learning by reading. Some accounting students do not attend class lectures because of the availability of the information posted on Blackboard. Accounting students, especially those at the lower level and taking introductory courses, should rely less on the use of static Blackboard because this makes them less likely to attend the lectures, and more likely to view the lecture slides on Blackboard. These students need to understand more basics of accounting which are acquired more through practice. The following statement derived from the interviews explained that:

I like to take courses in which instructors use Blackboard. I am able to use information posted on Blackboard to manage my learning strategy. I do not even need to attend class meetings because all information such as PowerPoint slides, tentative schedule containing the dates of exams and quizzes are available on Blackboard. I can use Blackboard to self-teach my accounting courses. Reading the information posted on Blackboard is sufficient.

We found a lack of a learning atmosphere in the students' use of static Blackboard. A positive learning ambience is a source of educational performance. It is difficult to maintain or create that learning atmosphere using static Blackboard because of reduced opportunities for contact or discussions with other students and teachers, and delayed feedback from instructors. The frequency of feedback seeking is very low when accounting students use static Blackboard. A highlight from our interviews shows how the students arrived at that decision: 
Every time, I have questions or concerns, I could not find an immediate clarification. I believe that lack of immediate clarification slows down my learning process because accounting topics are related to each other. The lack of concrete answers at the right moment does not help me to pursue my learning. It is even frustrating sometimes. The static Blackboard does not always give me an opportunity to interact with other students in the same class as me. This is another big issue because I like to exchange with my classmates on some topics but that opportunity is almost inexistent in static Blackboard.

Our findings indicate that the use of dynamic Blackboard and integrative Blackboard is more appropriate than static Blackboard for accounting students. Concerning the accounting students' use of dynamic Blackboard, we found that the benefits of Blackboard like the availability of information in real time, quick feedback such as instant grading, the improved communication, and improved two-way interactions favor efficient learning among accounting students. We found that students can access dynamic Blackboard at anytime and anywhere. Students can view and download course materials as well as submitting assignments online as soon as they are complete. A highlight from the findings includes:

I feel like I received quick feedback in the dynamic Blackboard. I am able to complete exercises interactively with my instructors. I also know when my instructors are online and choose that time to complete my assignments. I even do that whenever and wherever. The dynamic Blackboard provides instant grading, the teachers provide feedback instantly. My motivation is higher because I like to know my score and grades right away or as soon as possible. There are many tools dedicated to interactions on dynamic Blackboard. They facilitate communication between me and my instructors.

Concerning the accounting student's use of integrative Blackboard, we found that instructors can use integrated software on Blackboard like "Adobe Connect Professional" to teach, and students can be motivated to attend synchronized online sessions. Even though students may appreciate the convenience, students are generally satisfied with online learning using integrative Blackboard because it is like automated traditional face-to-face learning. The use of integrative Blackboard fits for teaching the introductory level accounting courses, where students should be provided an understanding of the basic financial and managerial accounting processes for sole proprietorships, partnerships and corporations. The use of integrative Blackboard boosts the basic level of understanding through the online and synchronized classroom discussions and problem solving. The students are able to apply the accounting principles in business situations. Also, they are able to evaluate the efficiency and effectiveness of a business by applying the accounting rules, principles and assumptions, etc. To be able to apply accounting rules, principles and assumptions requires a lot of practice of accounting problems. The experience is built from more practice; it is about retention. Most of students in the introductory accounting courses do not have any previous knowledge in accounting; those courses are new for most of them. The use of integrative Blackboard ensures that students keep participating in class. This is confirmed by the following declaration collected during the interview:

The use of integrative Blackboard is a kind of a distance-learning format that maximizes the level of contact with our instructors, as well as the level of discussion, among us (students). I understand that online learning gives me a freedom to decide when each online lesson will be learned. But the learning of accounting topics requires a lot of exercises, understanding of accounting rules and principles. It is why freedom to express thoughts, and ask questions, without limitations are required. Those conditions are usually met when I use integrative Blackboard in accounting classes. I remember using "WIMBA" to complete assignments in group where my teammates are not physically in the same place. I think integrative Blackboard can be seen as a very powerful collaborative learning and ideas generating platform that could be used to keep accounting students engaged and participative every time and everywhere.

Finally, we found that accounting students express concern about the level of security and privacy when using integrative Blackboard which is accessible with a password only to students. That indicates the level of confidentiality on integrative Blackboard. The use of username and password demonstrates how education institutions are able to manage confidential information of their students. This data protection safeguard is meant for checking the way universities personalize their relationship with their students via web sites. The following statement from the interview is used to support our analysis: 
I have some concerns about how secure is the integrative blackboard. I am still wondering how the degree of confidentiality and authentication on blackboard is related to FERPA. It does not mean that I am not feeling safe in my student records or education performance data available on Blackboard. I am just curious and I want to know whether or not some of the security standards and protocols for the Internet used to protect financial data and transactions are also available on the integrative Blackboard.

\section{CONCLUSIONS AND IMPLICATIONS}

The objective of this study is to conduct qualitative research to understand the impact of using Blackboard in accounting courses on students' performance. This objective raised important research questions. To answer these questions, interview data were collected from accounting students. We used content analysis to analyze the materials by reading them and looking for themes and patterns. We determined what categories spontaneously emerged from the data and then compared them to our conceptual framework. Then we drew a conclusion. We found that the use of dynamic and integrative Blackboard is more suitable to accounting students because of the difficult nature of accounting. The increased accessibility and availability of course resources are a key feature of Blackboard that accounting students should appreciate.

In terms of practical implications, the results of this study can be used by both accounting instructors and the students. The results will also allow the accounting instructors to know what Blackboard characteristics are appropriate to improve accounting students' learning ability and performance. The findings of this study should help accounting students to understand that static Blackboard is not the solution to pass accounting courses. Accounting students should learn lessons from this study in order to use the appropriate Blackboard resources and tools that should allow them to boost their academic performance.

In terms of theoretical implications, this research can be used to extend the applicability of the theory of creativity. This study demonstrates that the use of Blackboard in educational settings can be interpreted as activities that develop creativity.

There will be one notable limitation with the study. Even if a small percentage of accounting students maintain their academic information, it is unlikely they will make it available to researchers due to suspicions about the intended use. Future research is necessary because the use of information technology in education evolves so rapidly. Future research could also involve applying the conceptual framework to other majors or it could be used to compare majors.

\section{REFERENCES}

1. Al- Drees, A., Khalil, M. S., Meo, S. Y., and Abdulghani, H. M. (2014). Utilization of blackboard among undergraduate medical students: Where we are from the reality? Journal of Taibah University Medical Sciences, Article in Press, 1-5.

2. Bos, W. and Tarnai, C. (1999) Content analysis in empirical social research, International Journal of Educational Research, 31, 659-671.

3. Bradford P, Porciello M, Balkon N, Backus D. (2007). The blackboard learning system. Journal of Education Technology Systems, Vol. 35, pp. 301-314.

4. Chen A., Li L., Li X., Zhang J. \& Dong L. (2013). Study on Innovation Capability of College Students Based on Extenics and Theory of Creativity Procedia Computer Science, 17, $1194-1201$.

5. Donnelly, R., and O'Rouke, K., (2007) What now? Evaluating e-learning CPD practice in Irish third-level education. Journal of Further and Higher Education, 31, 31-40.

6. Heirdsfield, A., Davis, J., Lennox, S., Walker, S., \& Zhang, W. (2007). Online learning environments: what early childhood teacher education students say? Journal of Early Childhood Teacher Education, 28, 115-126.

7. Heirdsfield, A., Walker, S., Tambyah, M., Beutel, D. (2011). Blackboard As An Online Learning Environment: What Do Teacher Education Students and Staff Think? Australian Journal of Teacher Education, 36, 10-26.

8. Hew, K. F. and Cheun, W. S. (2013). Use of Web 2.0 technologies in K-12 and higher education: The search for evidence-based practice, Educational Research Review, Vol 9. pp. 47-64.

9. Jo K-H., An G. J. \& Sohn K. C. (2011). Qualitative content analysis of suicidal ideation in Korean college students, Collegian, 18, 87-92. 
10. Liaw, S-S (2008). Investigating students' perceived satisfaction, behavioral intention, and effectiveness of elearning: A case study of the Blackboard system. Computer and Education, 51, 864- 873.

11. Mishra A. K. \& Ramgopal M. (2014). A comparison of student performance between conditioned and naturally ventilated Classrooms, Building and Environment, In Press, Accepted Manuscript, Available online 17 November 2014, 30 pages.

12. Murphy, P. R. and Yoon, S. W. (2008). Good Practices in Accounting Education: Classroom Configuration and Technological Tools for Enhancing the Learning Environment, Accounting Education: an international journal, Vol. 17, No. 1, pp. 41-63.

13. Ozer I., Karpinski A. C. \& Kirschner P. A. (2014). A cross-cultural qualitative examination of socialnetworking sites and academic performance, Procedia - Social and Behavioral Sciences, 112, 873 - 881.

14. Rezaee, Z., Elam, R., and Cassidy, J. H. (2005) Electronic-commerce education: Insights from academians and practitioners. Advances in Accounting 21, 233- 258.

15. Stockwell P., Colomb R. M., Smith A. E. and Wiles J. (2009) Use of an automatic content analysis tool: A technique for seeing both local and global scope, Int. J. Human-Computer Studies 67, 424-436.

16. Suwardy, T. and Mavondo, F. (2003). "Integrating a virtual learning environment into an introductory accounting course: determinants of student motivation”, Accounting Education: an international journal, Vol. 12, No. 1, pp. 1-14. 